\title{
Epidemiology and medical cost of hospitalization due to rotavirus gastroenteritis among children under 5 years of age in the central-east of Tunisia
}

\author{
M.S. Soltani, ${ }^{1}$ A. Ben Salah, ${ }^{7}$ I. Bouanene, ${ }^{1}$ A. Trabelsi, ${ }^{2}$ M.T. Sfar, ${ }^{3}$ A. Harbi, ${ }^{4}$ M.N. Gueddiche ${ }^{5}$ and E. Ben Farhat ${ }^{6}$
}

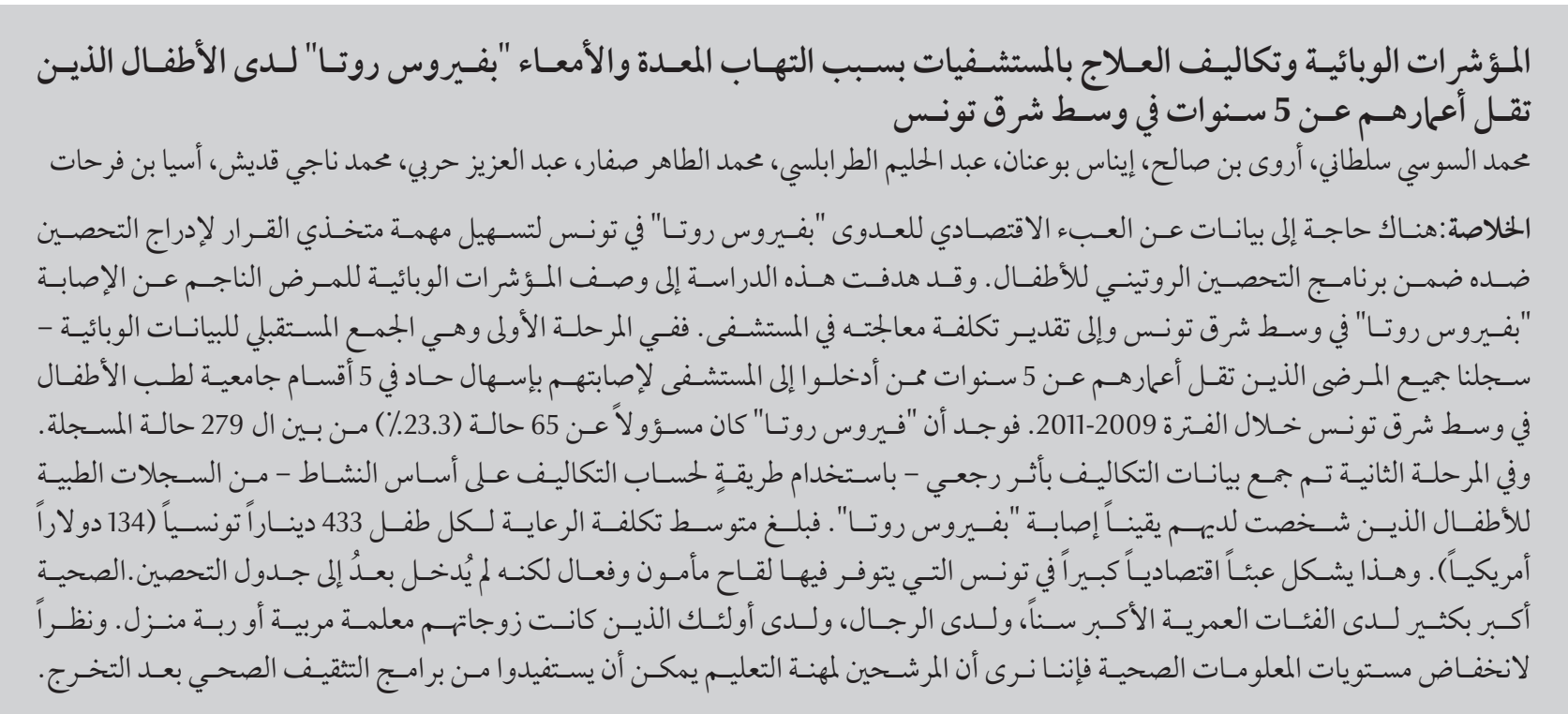

ABSTRACT Data on the economic burden of rotavirus infection in Tunisia are needed to inform the decision to include rotavirus in routine childhood immunizations. This study aimed to describe the epidemiological profile of rotavirus disease in central-east Tunisia and to estimate its hospital cost. In the first stage - the prospective collection of epidemiological data - we enrolled all patients < 5 years old who were hospitalized for acute diarrhoea at 5 university paediatric departments in central-east Tunisia during the period 2009-2011. Rotavirus was responsible for 65 (23.3\%) of the 279 cases enrolled. In the second stage, cost data were collected retrospectively using an activity-based costing method from the medical records of the children who were positively diagnosed with rotavirus. The average cost of care per child was TD 433 (SD 134). This is a significant economic burden in Tunisia, where a safe and effective vaccine is available but not yet introduced to the immunization schedule.

Épidémiologie et coût médical d'une hospitalisation pour une gastroentérite à rotavirus chez des enfants de moins de cinq ans dans le centre-est de la Tunisie

RÉSUMÉ Des données sur le fardeau économique de l'infection à rotavirus en Tunisie sont nécessaires pour décider ou non d'inclure le rotavirus dans les vaccinations infantiles systématiques. La présente étude visait à décrire le profil épidémiologique de l'infection à rotavirus dans le centre-est de la Tunisie et l'estimation de son coût hospitalier. Lors de la première phase, à savoir le recueil prospectif de données épidémiologiques, nous avons recruté tous les patients de moins de cinq ans ayant été hospitalisés pour une diarrhée aiguë dans cinq services pédiatriques universitaires du centre-est de la Tunisie entre 2009 et 2011. Le rotavirus était responsable de 65 cas sur 279 recrutés (23,3\%). Lors de la deuxième phase, des données sur les coûts ont été recueillies rétrospectivement à partir des dossiers médicaux des enfants qui étaient positifs au rotavirus, en utilisant une méthodologie de gestion des coûts par activité. Le coût moyen des soins par enfant était de 433 dinars tunisiens (ET 134). Ce montant représente un fardeau économique important en Tunisie, où un vaccin sûr et efficace existe mais n'est pas encore intégré dans le programme de vaccination.

${ }^{7}$ Department of Epidemiology and Preventive Medicine, University Hospital of Monastir; ${ }^{5}$ Department of Paediatrics, Monastir, Tunisia (Correspondence to A. Ben Salah: bensalah.arwa@yahoo.fr). ${ }^{2}$ Laboratory of Bacteriology-Virology; ${ }^{4}$ Department of Paediatrics, University Hospital of Sahloul, Sousse, Tunisia. ${ }^{3}$ Department of Paediatrics, University Hospital of Mahdia, Mahdia, Tunisia. ${ }^{6}$ Department of Basic Health Care, Ministry of Health, Ynis, Tunisia. Received: 08/07/14; accepted: 11/05/15 


\section{Introduction}

Rotavirus is the leading cause of severe diarrheal disease in young children. Worldwide, in 2008, diarrhoea attributable to rotavirus infection resulted in 453000 deaths (range 420000 to 494 000) in children younger than 5 years - i.e. 1 of every 260 children born each year will die before their fifth birthday from diarrhoea caused by rotavirus infection. Most of these deaths occur in developing countries in Africa and Asia (1). Even in high-resource countries, where rehydration therapy is accessible and deaths are rare, rotavirus gastroenteritis represents a public health problem and places a heavy economic burden on the health-care system (2).

In 2009, the World Health Organization (WHO) issued a global recommendation that rotavirus vaccine should be included in national immunization programmes (3). Two oral rotavirus vaccines (RotaTeq and Rotarix $\left.^{\mathrm{m}}\right)$ are currently available and have positively demonstrated safety and efficacy in clinical trials (4). However, the decision whether to incorporate the vaccine into routine schedules of childhood immunization in a country must include an objective assessment of the disease burden and an economic evaluation of the benefits of the vaccine's introduction.

In Tunisia, epidemiological data on rotavirus were previously presented and analysed by Soltani et al. However, data on the economic burden of rotavirus gastroenteritis in the country are lacking, which makes difficult any decision or rational reflection on the relevance of introducing the vaccine into routine childhood immunization schedules. This study was conducted in order to describe the epidemiological profile of rotavirus disease in the central-east region of Tunisia and to estimate the medical costs of hospitalization, in an effort to provide sufficient data to help policy-makers to assess the need for rotavirus vaccine.

\section{Methods}

The study was conducted in 2 stages. The first concerned the collection of epidemiological data, while in the second stage data were collected about the cost of hospital care for the disease.

\section{Epidemiological data}

This study was part of sentinel hospital surveillance established in the Eastern Mediterranean Region under the auspices of the WHO. In Tunisia, there were 11 sites comprising 11 paediatric departments that belong to 11 public hospitals located in different regions of the country: Tunis (1 site), north-west (1 site), north-east ( 2 sites), central-east (5 sites) and mid-west (1 site) (5).

We prospectively collected epidemiological data by enrolling all patients less than 5 years of age who were hospitalized for acute diarrhoea at the 5 university paediatric departments in the central-east region of Tunisia during the period 1 June 2009 to 31 May 2011. Acute diarrhoea was defined as a decrease in consistency (loose or liquid) and/or an increase in frequency of bowel movements to 3 or more per 24 hours, typically lasting less than 7 days and no more than 14 days (6).

A case report form was completed for every eligible case. This covered demographic characteristics (age, sex and residence), details of the clinical manifestations of the disease, laboratory data and treatment given. A stool sample was taken from each child. The virological analysis of all these samples was performed at the laboratory of virology at Sahloul University Hospital by enzyme-linked immunosorbent assay (ELISA). Molecular characterization into $G$ and $P$ genotypes was carried out for rotavirus-positive samples by reverse transcription polymerase chain reaction (RT-PCR) at the same laboratory.

\section{Cost data}

Data for the cost analysis were collected retrospectively from the medical records of children who were positively diagnosed with rotavirus.

The activity-based costing method was used to estimate the total medical cost for each patient from the healthsystem perspective. The principle behind this method is as follows: products consume activities, which in turn consume resources and these resources are aggregated because they constitute a cost (7). Hospitalization due to rotavirus gastroenteritis consumes different resources that can be grouped into 3 main categories according to the resulting activities: resources used in biology and radiology diagnostic activities (e.g. laboratory kits, materials and equipment, medical and paramedical staff, electricity); resources used in therapeutic activities (e.g. drugs and pharmaceutical products); and resources used during hospital stay (e.g. restaurant, laundry, hotel, electricity).

\section{Cost of biology and radiology diag- nostic activities}

For each patient, all the biological tests and radiological diagnostic procedures were listed and converted to a number of $B$ units for biology and $\mathrm{R}$ units for radiology, according to a predetermined weighting provided by the Tunisian Ministry of Health; for example: Creactive protein test $=80 \mathrm{~B}$, complete blood count $=60 \mathrm{~B}$, chest X-ray $=25$ $\mathrm{R})$. The average costs in Tunisian dinar (TD) of $1 \mathrm{~B}$ unit $=0.2 \mathrm{TD}$ and $1 \mathrm{R}$ unit $=0.9 \mathrm{TD}$ were estimated at the University Hospital of Monastir in 2008 using activity-based costing method. For this, all resources used by the laboratory and the radiology department during 2008 (laboratory kits, medical and paramedical staff salaries, electricity and all ingredients used in the laboratory or in the radiology department) and the number of $B$ and $R$ units produced during the same period were considered to calculate unit costs. So for each patient, the total cost of biology tests and radiology diagnostic procedures were calculated by multiplying the number of $\mathrm{B}$ or $\mathrm{R}$ 
units consumed by the average unit cost of $\mathrm{B}$ or $\mathrm{R}$

\section{Cost of therapeutic activities}

For each child, all drugs and pharmaceutical products received were listed and the doses were calculated by referring to medical records. The total cost per child was calculated by multiplying the total dose received by the price of the product which the hospital paid from the supplier prices for that period.

\section{Cost of hospital stay}

Daily bed cost was estimated by multiplying the length of stay by cost of hospital bed/day in a paediatric department, which is estimated at $30 \mathrm{TD}$ by the Tunisian Ministry of Health using activity-based costing. This includes restaurant, laundry, hotel, electricity and medical and paramedical staff salaries.

\section{Data analysis}

Statistical analyses were performed using SPSS software, version 17. The chisquared and Fisher exact tests were used to compare qualitative data. One-way analysis of variance and Tukey multiple comparisons were carried out to test for any significant differences between the means. $P$ values $\leq 0.05$ were considered to be statistically significant. Cost data were presented as total and mean and standard deviation (SD).

\section{Results}

\section{Study participants}

Between 1 June 2009 and 31 May2011, 279 children less than 5 years of age, hospitalized in one of the 5 paediatric departments of the central-east of Tunisia, were enrolled in the study. Out of these, 116 (59.5\%) were male and 259 (92.8\%) were aged less than 2 years old (Table 1).

\section{Rotavirus detection}

Rotavirus was detected in 65 (23.3\%) of stool samples screened.

\section{Strain}

For 39 (60.0\%) of these rotavirus-positive specimens, we were able to assign $G$ and $P$ types (26 specimens were not typeable). Of the 30 characterized $\mathrm{G}$ types, G3 was the most common $(n=$ 13) followed by G4 $(n=12)$ and $\mathrm{Gl}$ $(n=4)$. The most common P type was P8 $(n=28)$. P6 and P4 were found in 6 and 4 strains respectively. G4P8 was the most common type of specimens typed P and G $(n=11)$, followed by G3P8 ( $n$ $=10)$.

\section{Seasonality}

Rotavirus gastroenteritis showed a distinct seasonal pattern, with a peak during the winter period; more than half of all rotavirus cases (64.6\%) were reported between December and February (Figure 1).

\section{Age}

The mean age of children with acute gastroenteritis attributable to rotavirus was 9.4 months. The proportion of rotavirus-positive acute gastroenteritis cases varied by age, and was highest among children 6-23 months old (73.5\%). The cumulative age distribution showed that the majority of rotavirus gastroenteritis cases occurred by the age of 24 months (Figure 2).

\section{Clinical characteristics and clinical course}

Significantly more of the children positive for rotavirus had vomiting, dehydration and respiratory disorders than did children with acute gastroenteritis not attributable to rotavirus (Table 2). Among rotavirus-positive acute gastroenteritis cases, 36 children were dehydrated, half of whom were in stage 2. Intravenous rehydration was administrated to 28 patients. The resolution was favourable for all hospitalized children and no deaths were reported.

\section{Health-care utilization and hospital cost}

The mean duration of hospital stay for children with rotavirus gastroenteritis was 6 days (median 4 days; range 1-45 days). The total cost among these children was 28124 TD. Overall cost data are summarized in Table 2. The mean cost of hospitalization per child admitted with rotavirus diarrhoea was 433 (SD 134) TD [US \$274 (SD 87)]

\begin{tabular}{|c|c|c|}
\hline \multicolumn{3}{|c|}{$\begin{array}{l}\text { Table } 1 \text { Sociodemographic features of children hospitalized for acute } \\
\text { gastroenteritis }(n=279) \text { in the central-east of Tunisia, } 1 \text { June } 2009 \text { to } 31 \text { May } 2011\end{array}$} \\
\hline Variable & No. & $\%$ \\
\hline \multicolumn{3}{|l|}{ Age groups (months) } \\
\hline $0-5$ & 81 & 28.8 \\
\hline $6-11$ & 99 & 35.6 \\
\hline $12-23$ & 79 & 28.4 \\
\hline$\geq 24$ & 20 & 7.2 \\
\hline \multicolumn{3}{|l|}{ Sex } \\
\hline Male & 166 & 59.5 \\
\hline Female & 113 & 40.5 \\
\hline \multicolumn{3}{|l|}{ Site/hospital } \\
\hline Kairouan & 104 & 37.3 \\
\hline Monastir & 60 & 21.5 \\
\hline Mahdia & 19 & 6.8 \\
\hline Sahloul, Sousse & 89 & 31.9 \\
\hline Farhat Hached, Sousse & 7 & 2.5 \\
\hline \multicolumn{3}{|l|}{ Breasfeeding } \\
\hline Yes & 212 & 76.1 \\
\hline No & 67 & 23.9 \\
\hline
\end{tabular}




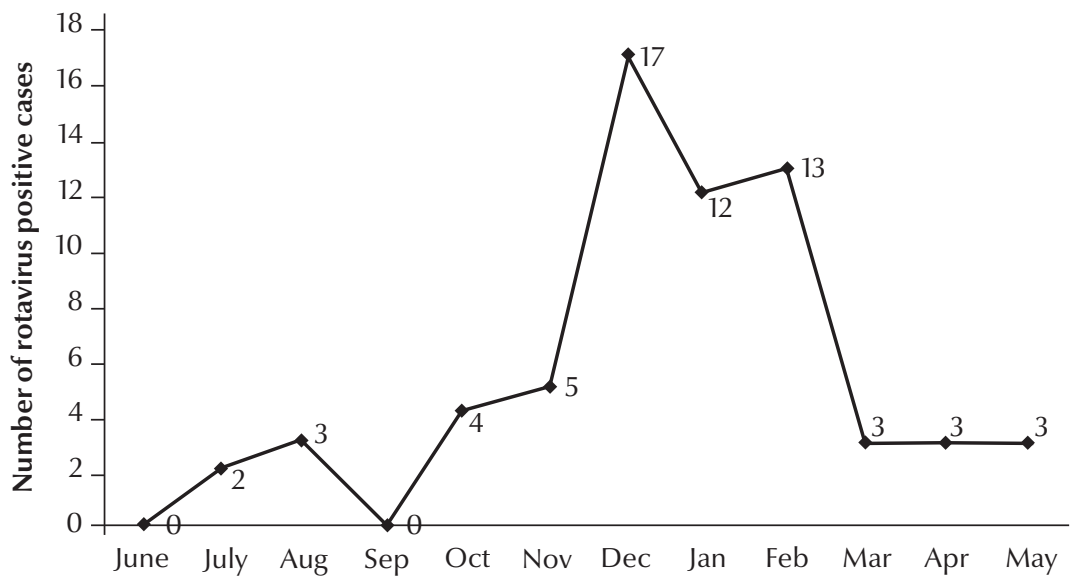

Figure 1 Seasonal distribution of cases of acute gastroenteritis attributable to rotavirus $(n=65)$ in the central-east of Tunisia, 1 June 2009 to 31 May 2011

ranging from 379 TD [US\$245] in Kairouan to 535 TD [US\$ 345] in Monastir, with a significant difference between the 2 sites $(P=0.012)$.

\section{Discussion}

This study was conducted in order to provide background data on rotavirus gastroenteritis and the hospital costs related to this disease. It showed that rotavirus was responsible for $23.3 \%$ of hospitalized cases of acute gastroenteritis among children $<5$ years of age in the central-east of Tunisia, with a peak occurring between December and February. From 1995 to 2005, 4 studies conducted in the same region of Tunisia have reported rotavirus rates ranging from $17.3 \%$ to $20.8 \%$ (8-11), confirming the endemicity of rotavirus-positive acute gastroenteritis cases in the region, and its rising trend.

Studies from other countries in the WHO Eastern Mediterranean Region have estimated the overall annual proportion of rotavirus cases among hospitalized cases of acute gastroenteritis in children $<5$ years old to range between $17 \%$ and $46 \%$ (12). Moreover, data collected through the global surveillance network for rotavirus in 2009 in 55 countries belonging to the $6 \mathrm{WHO}$ regions, revealed a median rate of rotavirus of 36\% (range 12\%-68\%) among enrolled and tested children aged $<5$ years hospitalized with diarrhoea (13). Our study results fall within these ranges. Differences between countries and regions can be explained by variations in hospital admission and health-care policies for children with gastroenteritis, accessibility to the health-care system and the use of different laboratory settings.

Rotavirus gastroenteritis mostly affected children from 6 to 23 months of age $(73.5 \%)$, which is consistent with previous observations of the epidemiological profile of rotavirus infection (14-16). This can be explained by the protection conferred by maternal antibodies before the age of 6 months

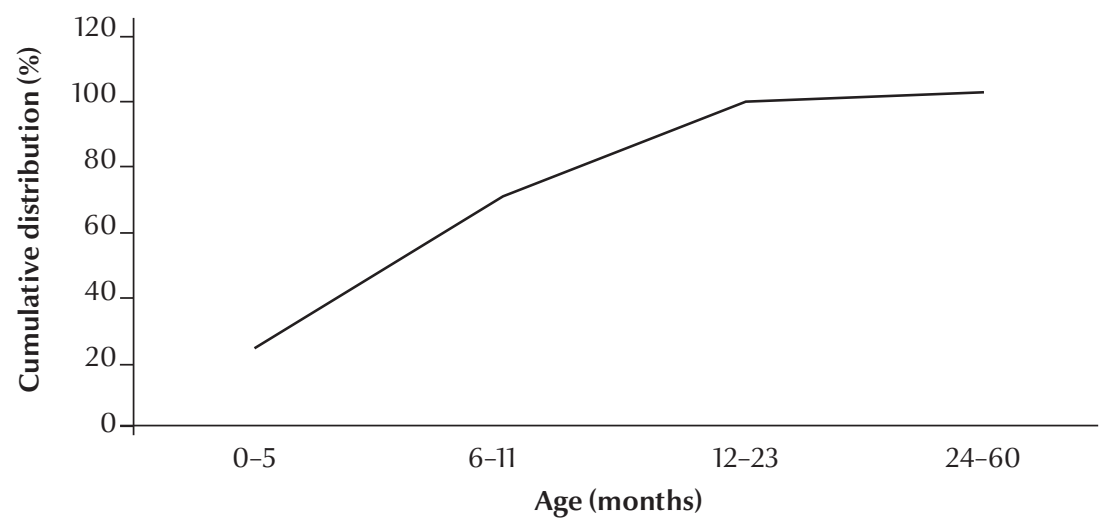

Figure 2 Cumulative age distribution of cases of acute gastroenteritis attributable to rotavirus $(n=65)$ in the central-east of Tunisia, 1 June 2009 to 31 May 2011 


\begin{tabular}{|c|c|c|c|}
\hline \multirow[t]{2}{*}{ Clinical presentation } & $\begin{array}{l}\text { Rotavirus-positive } \\
\text { patients } \\
(n=65)\end{array}$ & $\begin{array}{l}\text { Rotavirus-negative } \\
\text { patients } \\
(n=214)\end{array}$ & $P$-value ( $\chi^{2}$-test) \\
\hline & $\%$ & $\%$ & \\
\hline Fever & 64.6 & 58.8 & 0.4 \\
\hline Vomiting & 69.2 & 47.7 & 0.002 \\
\hline Dehydration & 64.6 & 36.9 & $<0.001$ \\
\hline Ionic disorder & 23.0 & 17.3 & 0.3 \\
\hline Respiratory disorder & 40.0 & 24.7 & 0.02 \\
\hline Neurological disorder & 26.1 & 25.2 & 0.88 \\
\hline
\end{tabular}

and by the immunity acquired after repeated infections after the age of 2 years (17), and emphasizes the importance of implementing preventive strategies early in life.

WHO recommends that the first dose of either Rotateq or Rotarix be administered at age 6-15 weeks and the last dose should be before 32 weeks (18). Rotavirus vaccination has been associated with protection against severe rotavirus disease of $85-100 \%$ in high- and middle-income countries and $46-77 \%$ in low-income countries in Africa and Asia (19).

In this study, the most common genotypes were G3, G4 and P8. G4P8 was the predominant single $G / P$ combination. This result suggests a modification in the circulating strain of the virus in this region where $\mathrm{Gl}$ and G1P8 used to be the predominated strains (9). Furthermore, all the strains identified in this study are targeted by the current available vaccines (Rotateq and Rotarix) (20), which highlights the need for these vaccines in our country.

Information about the cost of rotavirus infection in the literature is limited and a direct comparison with available studies is difficult. There is in fact great variability in the socioeconomic environment and approaches to health-care delivery across regions (21). Even the accounting methods used are different. In the Middle East and North Africa, the direct medical cost per episode of rotavirus gastroenteritis ranges from US\$ 467 to US\$ 1117 (22). In Asia, the average direct medical cost (adjusted to US\$2009) ranged from US\$20 per child in Viet Nam to US\$ 2142 per child in Hong Kong (23), and in Europe it ranged from $€ 1217$ (US\$ 826) in the United Kingdom to $€ 1515$ (US\$ 1028) in Sweden (24). In this study, the average direct medical cost per rotavirus $G$ admission was 433 TD (US\$274). The share of health care in Tunisia that is financed out-of-pocket varies

\begin{tabular}{lc}
\hline $\begin{array}{l}\text { Table } 3 \text { Total cost of care for acute gastroenteritis rotavirus-positive infection } \\
\text { among children aged less than } \mathbf{5} \text { years old }(\boldsymbol{n}=\mathbf{6 5}) \\
\text { of Tunisia }\end{array}$ \\
\hline Cost variables & Mean (SD) cost (TD) \\
Bed & $149(95)$ \\
Laboratory tests & $243(62)$ \\
Radiology & $20(13)$ \\
Medication & $16(11)$ \\
Total & $433(134)$ \\
\hline
\end{tabular}

${ }^{I}$ Tunisian dinar $(T D)=$ US\$ 0.652 at the time of analysis.

$S D=$ standard deviation .

depending on whether the patient has health insurance. Households with no health insurance have to pay the total amount, which represents $75 \%$ of the average monthly income of Tunisian citizens [estimated as US\$ 375 (25)] and 400\% of their monthly expenditure on health [estimated as US\$ 68.5 (26)]. In Tunisia, treating a hospitalized rotavirus-positive acute gastroenteritis case would cost 3 times the price of the vaccine, which is 150 TD for both doses of Rotarix.

Non-medical direct costs, which include transportation, nutrition, extra diapers and other expenses, and indirect costs, which include caregivers' productivity lost due to a child's hospitalization, were not included in this study, and it is therefore an underestimate of the real cost. In fact, according to a prospective study conducted in eastern China, the direct medical cost of rotavirus care was estimated at US\$ 460, while non-direct medical costs and indirect costs were estimated at US\$224, increasing the total cost by $50 \%$ (27). Another limitation is that this study did not include costs associated with rotavirus diarrheal episodes for children cared for at home. Considering these costs would increase the economic burden of rotavirus infection and further highlight the need of rotavirus vaccines as an important measure to reduce the morbidity and economic burden that rotavirus diarrhoea places on affected families and on the government. 
The use of rotavirus vaccine needs to be part of a comprehensive strategy to control diarrheal diseases, This strategy should include, among other interventions, improvements in hygiene and sanitation, providing safe drinking water, promoting breastfeeding, community-based administration of oral rehydration solution and overall improvements in case management (18).

In conclusion, the economic burden of rotavirus gastroenteritis seems to be major in Tunisia, where a safe and effective vaccine is available but has not yet been introduced to immunization schedules. In this context, cost-effectiveness studies would be helpful to inform policy-makers to take appropriate decisions.

\section{Acknowledgements}

Funding: WHO provided some funding for the sentinel hospital surveillance.

Competing interests: None declared.

\section{References}

1. Tate JE, Burton AH, Boschi-Pinto C, Steele AD, Duque J, Parashar UD; WHO-coordinated Global Rotavirus Surveillance Network. 2008 estimate of worldwide rotavirus-associated mortality in children younger than 5 years before the introduction of universal rotavirus vaccination programmes: a systematic review and meta-analysis. Lancet Infect Dis. 2012 Feb;12(2):136-41. PMID:22030330

2. Widdowson MA, Meltzer MI, Zhang X, Bresee JS, Parashar UD, Glass RI. Cost-effectiveness and potential impact of rotavirus vaccination in the United States. Pediatrics. 2007 Apr;119(4):684-97. PMID:17403839

3. Danchin $\mathrm{MH}$, Bines JE. Defeating rotavirus? The global recommendation for rotavirus vaccination. N Engl J Med. 2009 Nov 12;361(20):1919-21. PMID:19907040

4. Soares-Weiser K, Maclehose H, Bergman H, Ben-Aharon I, Nagpal S, Goldberg E, et al. Vaccines for preventing rotavirus diarrhoea: vaccines in use. Cochrane Database Syst Rev. 2012;11:CD008521. PMID:23152260

5. Soltani M, Bouanene I, Trabelsi A, Harbi A, Hachicha M, Amri $\mathrm{F}$, et al. [Epidemiology of rotavirus gastroenteritis among children under 5 years of age in Tunisia - results of sentinel hospital surveillance 2009 to 2011]. Rev Epidemiol Sante Publique. 2012 Dec;60(6):473-80. PMID:23141818

6. Guarino A, Albano F, Ashkenazi S, Gendrel D, Hoekstra JH, Shamir R, et al.; European Society for Paediatric Gastroenterology, Hepatology, and Nutrition; European Society for Paediatric Infectious Diseases. Evidence-based guidelines for the management of acute gastroenteritis in children in Europe. J Pediatr Gastroenterol Nutr. 2008 May;46 Suppl 2:S81-122. PMID:18460974

7. Sorin B, Sorinel C. Effective cost analysis tools of the activitybased costing $(\mathrm{ABC})$ method. Annales Universitatis Apulensis Series Oeconomica. 2010;1(12):25-35.

8. Trabelsi A, Peenze I, Pager C, Jeddi M, Steele D. Distribution of rotavirus VP7 serotypes and VP4 genotypes circulating in Sousse, Tunisia, from 1995 to 1999: emergence of natural human reassortants. J Clin Microbiol. 2000 Sep;38(9):3415-9. PMID:10970394

9. Chouikha A, Fodha I, Noomen S, Bouzid L, Mastouri M, Peenze I, et al. Group A rotavirus strains circulating in the eastern center of Tunisia during a ten-year period (1995-2004). J Med Virol. 2007 Jul;79(7):1002-8. PMID:17516524

10. Fodha I, Chouikha A, Peenze I, De Beer M, Dewar J, Geyer $A$, et al. Identification of viral agents causing diarrhea among children in the Eastern Center of Tunisia. J Med Virol. 2006 Sep;78(9):1198-203. PMID:16847966

11. Chouikha A, Fodha I, Bouslama L, Ben Hadj Fredj M, Jaoua S, Boujaafar N, et al. Emergence and characterization of human rotavirus g9 strains in Tunisia. J Infect Dis. 2009 Nov 1;200 Suppl 1:S239-43. PMID:19817604
12. Malek MA, Teleb N, Abu-Elyazeed R, Riddle MS, Sherif ME, Steele AD, et al. The epidemiology of rotavirus diarrhea in countries in the Eastern Mediterranean Region. J Infect Dis. 2010 Sep 1;202 Suppl:S12-22. PMID:20684691

13. Centers for Disease Control and Prevention (CDC). Rotavirus surveillance --- worldwide, 2009. MMWR Morb Mortal Wkly Rep. 2011 Apr 29;60(16):514-6. PMID:21527889

14. Van Damme P, Giaquinto C, Huet F, Gothefors L, Maxwell M, Van der Wielen M; REVEAL Study Group. Multicenter prospective study of the burden of rotavirus acute gastroenteritis in Europe, 2004-2005: the REVEAL study. J Infect Dis. 2007 May 1;195 Suppl 1:S4-16. PMID:17387650

15. Kamiya H, Nakano T, Inoue M, Kamiya H, Abd TT, Patel M, et al. A retrospective evaluation of hospitalizations for acute gastroenteritis at 2 sentinel hospitals in central Japan to estimate the health burden of rotavirus. J Infect Dis. 2009 Nov 1;200 Suppl 1:S140-6. PMID:19817592

16. Khalil M, Azhar E, Kao M, Al-Kaiedi N, Alhani H, Al Olayan I, et al. Gastroenteritis attributable to rotavirus in hospitalized Saudi Arabian children in the period 2007-2008. Clin Epidemiol. 2015;7:129-37. PMID:25709500

17. Jiang B, Gentsch JR, Glass RI. The role of serum antibodies in the protection against rotavirus disease: an overview. Clin Infect Dis. 2002 May 15;34(10):1351-61. PMID:11981731

18. Immunization, Vaccines and Biologicals. Rotaviruses [Internet]. Geneva: World Health Organization (http://www. who.int/immunization/topics/rotavirus/en/index.html, accessed 3 June 2015).

19. Grimwood K, Lambert SB, Milne RJ. Rotavirus infections and vaccines: burden of illness and potential impact of vaccination. Paediatr Drugs. 2010 Aug 1;12(4):235-56. PMID:20593908

20. Leshem E, Lopman B, Glass R, Gentsch J, Bányai K, Parashar $U$, et al. Distribution of rotavirus strains and strain-specific effectiveness of the rotavirus vaccine after its introduction: a systematic review and meta-analysis. Lancet Infect Dis. 2014 Sep;14(9):847-56. PMID:25082561

21. Chen KT, Fan SF, Tang RB, Huang YF, Lee PI, Chen PY, et al. Hospital-based study of the economic burden associated with rotavirus diarrhea in Taiwan. Vaccine. 2007 May 22;25(21):4266-72. PMID:17360079

22. Khoury H, Ogilvie I, El Khoury AC, Duan Y, Goetghebeur MM. Burden of rotavirus gastroenteritis in the Middle Eastern and North African pediatric population. BMC Infect Dis. 2011;11:9. PMID:21214934

23. Kawai K, O'Brien MA, Goveia MG, Mast TC, El Khoury AC. Burden of rotavirus gastroenteritis and distribution of rotavirus strains in Asia: a systematic review. Vaccine. 2012 Feb 8;30(7):1244-54. PMID:22212128 
24. Giaquinto C, Van Damme P, Huet F, Gothefors L, Van der Wielen M; REVEAL Study Group. Costs of community-acquired pediatric rotavirus gastroenteritis in 7 European countries: the REVEAL Study. J Infect Dis. 2007 May 1;195 Suppl 1:S36-44. PMID:17539193

25. Tunisia [Internet]. New York: The World Bank; 2011 (http:// www.worldbank.org/en/country/tunisia, accessed 3 June 2015).
26. Statistical data bank [Internet]. Tunis: National Institute of Statistics Tunisia (http://www.ins.nat.tn/indexen.php, accessed 3 June 2015).

27. Jin H, Wang B, Fang Z, Duan Z, Gao Q, Liu N, et al. Hospitalbased study of the economic burden associated with rotavirus diarrhea in eastern China. Vaccine. 2011 Oct 13;29(44):7801-6. PMID:21843578 